http://dx.doi.org/10.18675/1981-8106.vol25.n48.p129-149

\title{
Dificuldades de alunos respiradores orais na resolução de problemas matemáticos do tipo aditivo
}

\section{Difficulties of mouth-breathing students in the solution of additive mathematical problems}

\section{Dificultades de alumnos respiradores orales en la resolución de problemas matemáticos del tipo aditivo}

\author{
Olinda Teruko Kajihara' \\ Juliana Godoi Kazakevich" \\ Vanderly Janeiro "II \\ 'Universidade Estadual de Maringá (UEM), Paraná - Brasil. E-mail: olindakajihara@hotmail.com \\ " Faculdade Instituto Superior de Educação do Paraná (INSEP), Paraná - Brasil. E-mail: \\ ju_kzk@hotmail.com \\ I"Universidade Estadual de Maringá (UEM), Paraná - Brasil. E-mail: vjaneiro@uem.br
}

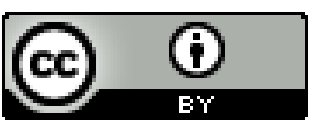

Educação: teoria e prática, Rio Claro, SP, Brasil - eISSN: 1981-8106

Está licenciada sob Licença Creative Common

\section{Resumo}

Neste estudo, foram avaliados 26 alunos com características de respiração oral e seus 42 colegas de classe, do terceiro ano do Ensino Fundamental, em uma tarefa de resolução de 13 problemas do tipo aditivo. O desempenho dos respiradores orais na tarefa foi inferior ao de seus colegas de classe (Teste t Pareado, $\mathrm{p}<0,00$ ). A análise intergrupos revelou que a proporção de erros de atenção cometidos pelos respiradores orais $(30,13 \%)$ foi maior que a de seus colegas de classe $(18,90 \%$; Teste para Comparação de Duas Proporções, $\mathrm{p}<0,00)$. Os respiradores orais cometeram proporções semelhantes de erros de atenção e de interpretação (Teste Binomial Exato, $\mathrm{p}<0,25$ ), e os seus colegas de classe, mais erros de interpretação que de atenção $(\mathrm{p}<0,00)$. As dificuldades de atenção e de interpretação foram os principais fatores que levaram os respiradores orais a errarem, em média, 66\% dos problemas; e a 
dificuldade de interpretação das situações aditivas foi o principal fator que levou os colegas de classe a errarem, em média, $43 \%$ dos problemas. O tratamento precoce da respiração oral pode impedir prejuízos no desenvolvimento e na aprendizagem e, por isso, é importante que o professor oriente os familiares dos respiradores orais a buscarem ajuda de um especialista.

Palavras-chave: Respiração oral; Problemas aditivos; Dificuldades de atenção.

\begin{abstract}
Twenty-six mouth-breathing students and their 42 class mates from the third stage of a lower junior school were evaluated in a solution task involving 13 additive problems. Task performance of mouth-breathing students was lower than that by class colleagues (Paired $t$ Test, $p<0.00)$. Intergroup analysis revealed that the proportion of attention mistakes by mouth-breathing students (30.13\%) was higher than that of class mates (18.90\%; Test for Comparison of Two Proportions, $p<0.00)$. Mouth-breathing students performed similar proportions of attention and interpretation mistakes (Exact Binomial Test, $p<0.25$ ), whereas their colleagues made more interpretation than attention mistakes $(p<0.00)$. Attention and interpretation difficulties were the main factors that made mouth-breathing students to commit mistakes, at an average of 66\% of the problems. Interpretation difficulty in addition situations was the main factor that made their class mates to commit mistakes, at an average of $43 \%$ of the problems. Since early treatment of mouth-breathing may hinder losses in development and learning, it is highly relevant that the teacher counsels the parents of mouthbreathing children to seek expert help.
\end{abstract}

Keywords: Mouth-breathin; Additive problems; Attention difficulties.

\title{
Resumen
}

En este estudio, se evaluaron 26 alumnos con características de respiración oral y sus 42 compañeros de clase, del tercer año de la Enseñanza Fundamental, en una tarea de resolución de 13 problemas del tipo aditivo. El desempeño de los respiradores orales en la tarea fue inferior al de sus compañeros de clase (Test t Pareado, $p<0,00$ ). El análisis intergrupos reveló que la proporción de errores de atención cometidos por los respiradores orales (30,13\%) fue mayor que la de sus compañeros de clase (18,90\%; Test para Comparación de Dos Proporciones, $p<0,00)$. Los respiradores orales cometieron proporciones semejantes de errores de atención y de interpretación (Test Binomial Exacto, $p$ $<0,25)$, y sus compañeros de clase, más errores de interpretación que de atención ( $p<0,00)$. Las dificultades de atención y de interpretación fueron los principales factores que llevaron a los respiradores orales a equivocarse, en media, en el 66\% de los problemas; y la dificultad de interpretación de las situaciones aditivas fue el principal factor que llevó a los compañeros de clase a errar, en promedio, $43 \%$ de los problemas. El tratamiento precoz de la respiración oral puede impedir perjuicios en el desarrollo y en el aprendizaje y, por eso, es 
importante que el profesor oriente a los familiares de los respiradores orales a buscar la ayuda de un especialista.

Palabras clave: Respiración oral; Problemas aditivos; Dificultades de atención.

\section{Introdução}

No final da década de 1990, os Parâmetros Curriculares Nacionais (PCN) propuseram que questões sociais relevantes fossem incorporadas ao currículo e trabalhadas como temas transversais: saúde, ética, meio ambiente, orientação sexual e pluralidade cultural (BRASIL, 1997a). Em relação ao primeiro tema, a escola deve assumir a responsabilidade pela "educação para a saúde", e atuar no sentido de "conscientizar os alunos para o direito à saúde", e sensibilizá-los para a "compreensão de seus determinantes e capacitá-los para a utilização de medidas práticas de promoção, proteção e recuperação da saúde ao seu alcance" (BRASIL, 1997b, p.71). Dessa forma, a escola deve estar atenta aos fatores orgânicos que interferem no desenvolvimento infantil e na aprendizagem escolar, como, por exemplo, as doenças que provocam obstrução nasal.

A rinite alérgica é a principal causa de obstrução das vias aéreas superiores, seguida pela hipertrofia das tonsilas palatinas e faríngeas (LUZZI et al., 2013). A rinite alérgica é um problema de saúde global que afeta de $10 \%$ a $20 \%$ da população mundial (BROZEK et al., 2010). Nos Estados Unidos, essa doença é responsável, anualmente, por 3,5 milhões de dias de faltas no trabalho e por 2 milhões de faltas nas escolas (NATHAN, 2007).

A rinite alérgica consiste na inflamação da mucosa nasal decorrente de exposição aos alérgenos: ácaros da poeira, pólen de plantas, pelos de animais etc. A rinite é caracterizada por congestão nasal, espirros em salva, rinorreia aquosa e prurido no nariz (SOLÉ; SAKANO, 2012). A congestão dos tecidos cavernosos das conchas nasais provoca obstrução nasal (COREY; HOUSER; NG, 2000).

As tonsilas faríngeas (ou adenoides) estão localizadas na nasofaringe e atuam na defesa do organismo (PORTINHO, 1999). Em alguns casos, aumentam exageradamente por causa de infecções, e passam a obstruir as vias aéreas (ENDO, 2000). Os principais sintomas dessa doença são: obstrução nasal, respiração oral, voz anasalada, rinorreia, sialorreia, ronco noturno e sono agitado (PORTINHO, 1999).

As tonsilas palatinas (ou amídalas), localizadas na orofaringe, também atuam na defesa do organismo e, por causa de infecções, podem sofrer hipertrofia e provocar obstrução nasal (PORTINHO, 1999). Os principais sintomas dessa enfermidade são: mal-estar, febre, tosse, vômito, falta de apetite e dificuldade de deglutição (SÁ FILHO, 1994).

A congestão e a obstrução da via aérea nasal obrigam a pessoa a respirar pela boca (COREY; HOUSER; NG, 2000). No final do século XIX, Tomes (1872 apud RUBIN, 1979) introduziu o termo face adenoideana para denominar as alterações craniofaciais decorrentes 
da respiração oral provocada pelo crescimento excessivo das tonsilas faríngeas. A criança com face adenoideana apresenta boca aberta, narinas pequenas e mal desenvolvidas, lábio superior curto, dentes incisivos superiores proeminentes e inclinados para frente, lábio inferior estirado (em sinal de amuo), olhar vazio, arco dentário superior estreito, abóbada palatina alta e má oclusão dos dentes (McNAMARA, 1981).

A respiração, para ser realizada oralmente, exige mudanças musculares. A língua desloca-se para baixo e para frente e, portanto, longe do palato mole (SUBTELNY, 1954). Quando a boca permanece aberta, os músculos que abaixam a mandíbula durante a inspiração puxam-na, também, para trás. Com o decorrer do tempo, isso pode modificar a mandíbula e os dentes molares inferiores, que passam a posicionar-se distalmente, o que provoca má oclusão (McCOY; SHEPHARD, 1956).

O lábio superior é pouco usado pelo respirador oral, e exerce pouca influência sobre os dentes superiores anteriores; o lábio inferior, ao invés de obrigar o abaixamento dos incisivos superiores, volta-se para fora. Por causa da má relação entre os arcos dentários, o lábio inferior pode passar a descansar entre eles, e os dentes superiores e anteriores podem ser puxados para frente (McCOY; SHEPHARD, 1956).

No respirador oral, a cabeça é estendida ou inclinada para trás para aumentar a via aérea (RICKETTS, 1968) e, assim, facilitar a respiração (SOLOW; SIERSBAEK-NIELSEN, 1992). A má oclusão dos dentes é acompanhada de problemas de mastigação, de deglutição e de fala (McCOY; SHEPHARD, 1956). É por isso que o respirador oral apresenta dificuldade em comer e respirar ao mesmo tempo; normalmente prefere alimentos macios que requerem pouca mastigação, ou mastiga com a boca aberta. A dificuldade em respirar pelo nariz e a rinorreia diminuem o olfato e o prazer em se alimentar, e favorecem a diminuição do apetite. Esses problemas nutricionais contribuem para a baixa estatura e o baixo peso (POTSIC, 1992).

O impacto da respiração oral no desenvolvimento é tão grande que, entre os 3 e 4 anos, as crianças podem apresentar má oclusão dentária (BREUER, 1989). Além disso, também é possível observar alterações orgânicas, conforme registrado por Kazakevich, Neves e Kajihara (2008). Estes pesquisadores verificaram, em um grupo de 129 crianças, de 3 a 5 anos, de Paiçandu - PR, 87 com histórico de doenças obstrutivas das vias aéreas e, pelo menos, três características típicas de respiradores orais.

Além desses efeitos precoces da respiração oral no organismo infantil, estudos realizados pelo Grupo de Pesquisa "Ensino, Aprendizagem e Avaliação Escolar", da Universidade Estadual de Maringá, com vários grupos de respiradores orais do quarto, quinto e sexto anos do Ensino Fundamental, têm evidenciado associação entre modo respiratório oral, desatenção e dificuldades de matemática.

Considerando que os efeitos da respiração oral no organismo podem ser observados precocemente, na segunda infância, é necessário investigar se no início da escolarização os respiradores orais já apresentam dificuldades de matemática. Portanto, nesta pesquisa foi 
analisado o desempenho, em problemas do tipo aditivo, de um grupo de respiradores orais matriculados no terceiro ano do Ensino Fundamental.

\subsection{Dificuldades de matemática de alunos respiradores orais}

No início da década de 2000, começaram a ser realizadas pesquisas sobre as dificuldades escolares dos alunos respiradores orais. Na área da Educação, o Grupo de Pesquisa "Ensino, Aprendizagem e Avaliação Escolar", da Universidade Estadual de Maringá - Paraná, foi o primeiro a investigar esse tema.

Godoy (2003) avaliou 33 escolares de terceira e quarta séries do Ensino Fundamental, atendidos em Salas de Recursos de Maringá. Os estudantes apresentavam histórico de doenças obstrutivas das vias aéreas e características de respiração oral. Os resultados dos alunos com obstrução nasal foram comparados com os de seus 33 colegas de classe do Ensino Regular. Duas tarefas foram elaboradas e aplicadas: a primeira, composta por 17 operações de adição, de subtração, de multiplicação e de divisão; e a segunda, por oito problemas envolvendo as operações fundamentais. A média de erros dos alunos com obstrução nasal nos problemas foi superior à de seus colegas de classe (Teste de Spjotvoll e Stoline, $\mathrm{p}<0,00$ ).

Na resolução de operações, os escolares com obstrução nasal também apresentaram pior desempenho que os seus colegas $(\mathrm{p}<0,00)$, em decorrência de dificuldade de atenção ( $\mathrm{p}$ $<0,00$ ), que foi confirmada por meio de avaliação neuropsicológica: o grupo com obstrução nasal apresentou capacidade de atenção seletiva e sustentada inferior (Teste de Comparação de Duas Médias, $\mathrm{p}<0,00$ ) à das crianças do grupo de padronização do teste (GODOY, 2003).

Leal (2004) e Silva (2005) avaliaram, respectivamente, 30 escolares com hipertrofia das tonsilas faríngeas, e 30 alunos com rinite alérgica atendidos em uma clínica-escola de Odontologia de Maringá. Os alunos cursavam a terceira e quarta séries. Na resolução de problemas, a média de erros dos alunos com hipertrofia das adenoides foi superior (Teste de Spjotvoll e Stoline, $\mathrm{p}<0,00$ ) à do grupo de colegas de classe de Godoy (2003). O nível de dificuldade dos alunos com rinite foi semelhante a dos colegas de classe (Teste de Spjotvoll e Stoline, $\mathrm{p}<0,55)$ : estes erraram, em média, $42 \%$ dos problemas, e aqueles, $51 \%$.

Vinte e quatro participantes dos estudos de Leal (2004) e de Silva (2005) foram reavaliados, na quinta série, por Gomes (2007). Na terceira série, a média de erros dos 24 respiradores orais nos 8 problemas foi de 4,6, e na quinta série, de 3,8. Portanto, o nível de dificuldade não diminuiu da terceira para a quarta série (Teste t para Amostras Dependentes, $\mathrm{p}$ $=0,06$ ). As frequências de erros de atenção (Teste de Wilcoxon para Dados Emparelhados, $\mathrm{p}$ $=0,69)$ e no algoritmo $(\mathrm{p}=0,81)$ não diminuíram, mas a habilidade de interpretação melhorou na quinta série $(\mathrm{p}=0,02)$.

O impacto da respiração oral na aprendizagem da matemática é muito grande. Nishimura (2010) avaliou 30 respiradores orais de terceira e quarta séries, com histórico de hipertrofia das tonsilas faríngeas e/ou rinite alérgica, que haviam sido atendidos pelo setor de 
Otorrinolaringologia de um Posto de Saúde de Maringá. A pesquisadora constatou que as chances (odds ratio) de os respiradores orais apresentarem baixo desempenho na resolução de problemas de matemática são oito vezes maiores que as de seus colegas de classe; e as chances de os respiradores orais apresentarem erros de atenção, no algoritmo e de interpretação são 10, 2 e 9 vezes maiores que as de seus colegas.

\subsection{Recomendações dos Parâmetros Curriculares Nacionais para o ensino de problemas aditivos}

De acordo com os Parâmetros Curriculares Nacionais (PCN), elaborados na década de 1990, no primeiro e no segundo ciclos do Ensino Fundamental, o ensino da Matemática deve levar o aluno: a analisar, a interpretar, a resolver e a formular situações-problema; a compreender os significados das operações; a compreender que situações-problema podem ser resolvidas por operações, assim como diferentes operações podem ser utilizadas para resolver um problema (BRASIL, 1997b).

A teoria que fundamenta as recomendações dos PCN para o ensino de problemas matemáticos é a dos Campos Conceituais, de Gérard Vergnaud (2009). De acordo com os PCN, nas séries iniciais devem ser trabalhadas relações aditivas de transformação, de combinação, de comparação e de composição de transformações. Os problemas de transformação envolvem a ideia de mudança positiva (acréscimo) ou negativa (diminuição) de um estado inicial. Nos problemas aditivos de composição, duas ou mais transformações levam a outra transformação. As duas mudanças podem ser positivas, negativas ou positiva e negativa (BRASIL, 1997b).

Os problemas de transformação possibilitam formar seis classes de situações: busca do estado final de uma transformação positiva; busca do estado final de uma transformação negativa; busca do valor da transformação positiva; busca do valor da transformação negativa; busca do estado inicial de uma transformação positiva; e busca do estado inicial de uma transformação negativa (VERGNAUD, 2009).

Os problemas de combinação permitem formar duas classes de situações: busca da composta (terceiro estado ou todo), a partir da combinação de duas medidas elementares (partes); e busca de uma medida elementar, a partir do conhecimento da composta e de outra medida elementar (VERGNAUD, 2009). Em um quarto tipo de problemas aditivos ocorre uma comparação entre duas quantidades. A comparação pode ser positiva ou negativa (BRASIL, 1997b).

\section{Método}

A pesquisa explicativa, indicada para investigar fatores que contribuem para a ocorrência de fenômenos (GIL, 2008), permitiu, neste estudo, analisar se a respiração oral prejudicava a aprendizagem da matemática de crianças nos anos iniciais do Ensino 
Fundamental. O procedimento adotado para a coleta de dados foi o experimental (GIL, 2008), tendo sido comparado o desempenho, em uma tarefa de problemas matemáticos aditivos, de um grupo experimental com o de um grupo de controle.

Participaram do grupo experimental 26 alunos do terceiro ano do Ensino Fundamental, que estudavam em 14 turmas de 4 escolas municipais de Paiçandu - PR. Esses escolares, com histórico de doenças obstrutivas das vias aéreas, haviam participado, quando cursavam a Educação Infantil, do estudo de Kazakevich, Neves e Kajihara (2008), e na faixa etária de 3 a 5 anos, já apresentavam características típicas de respiradores orais.

Portanto, foi utilizado um delineamento longitudinal, em que o mesmo grupo de participantes foi analisado em mais de um momento, ao longo do tempo (MOTA, 2010), para investigar se a respiração oral, que afetou precocemente, já na segunda infância, o desenvolvimento dos respiradores orais, prejudicava, também, já no início da escolarização, a aprendizagem de problemas matemáticos aditivos.

Considerando a importância do fator pedagógico no desempenho escolar, os resultados dos alunos do grupo experimental (GRO) foram comparados com os de um grupo de controle, composto por 42 colegas de classe (GCC) dos respiradores orais, escolhidos por meio de sorteio.

Os pais ou responsáveis dos participantes assinaram o Termo de Consentimento Livre e Esclarecido, e a pesquisa foi aprovada (Parecer 0487) pelo Comitê de Ética em Pesquisa Envolvendo Seres Humanos, da instituição de ensino superior em que atuam os pesquisadores.

Para a elaboração da tarefa de matemática, foram analisados os problemas aditivos propostos nos livros didáticos utilizados pelos alunos no primeiro e no segundo anos, e nos cadernos escolares, do terceiro ano. Os livros continham 93 problemas aditivos: 34 de transformação, 27 de combinação, 24 de comparação e 8 de composição. Nos cadernos escolares havia 341 problemas: 120 de combinação, 36 de transformação positiva, 121 de transformação negativa, 33 de comparação e 31 de composição.

Houve uma grande variação entre as escolas, da quantidade de problemas aditivos trabalhados. As maiores quantidades de registros de problemas aditivos foram encontradas nos cadernos dos alunos da Escola III: no total, foram dados 235 problemas aditivos (21 na turma $A, 41$ na $B, 19$ na $C, 62$ na $D, 48$ na $E$ e 44 na $F$ ). A Escola que trabalhou menos esse conteúdo foi a II: 23 problemas (5 na turma $A, 9$ na $B$ e 8 na $D$ ).

Os 13 problemas aditivos elaborados para este estudo exigiram diferentes raciocínios aditivos:

1) Na escola de Ana há 123 meninos e 219 meninas. Quantos alunos há na escola? (busca do terceiro estado ou do todo de uma combinação).

2) João tinha 128 carrinhos. Ele ganhou mais 35. Com quantos carrinhos ficou? (busca do estado final de uma transformação positiva). 
3) Juca tinha 112 figurinhas. Ele perdeu algumas. Agora ele tem somente 104. Quantas figurinhas ele perdeu? (busca do valor de uma transformação negativa).

4) Marcos tem 24 anos. Sara tem 17 anos. Quem tem mais anos? Quantos anos a mais? (busca do valor da relação de uma comparação positiva).

5) Mariana tem 33 revistas. Caio tem 18 revistas a mais que Mariana. Quantas revistas tem Caio? (busca do referido de uma comparação positiva).

6) Maria ganhou 40 reais em seu aniversário, e com isso ficou com 95 reais. Quantos reais ela tinha antes do aniversário? (busca do estado inicial de uma transformação positiva).

7) Ana tem alguns brinquedos. Bruno tem 8 brinquedos a mais que Ana. No total, Bruno tem 26 brinquedos. Quantos brinquedos tem Ana? (busca do referente de uma comparação).

8) Em uma caixa, há 50 frutas. 23 frutas são maçãs e o restante são bananas. Quantas bananas há nessa caixa? (busca de uma das partes de uma combinação).

9) Paula tinha 18 bombons. Ela ganhou mais alguns de sua mãe e ficou com 25. Quantos bombons Paula ganhou? (busca do valor de uma transformação positiva).

10) No depósito do supermercado Bom Dia, há 408 latas de óleo. Nessa semana, 126 latas foram colocadas nas prateleiras do supermercado para serem vendidas. Quantas latas de óleo ainda têm no depósito? (busca do estado final de uma transformação negativa).

11) Lucas tem 293 bois em sua fazenda. Maria tem 75 bois a menos que Lucas. Quantos bois Maria tem em sua fazenda? (busca do referido de uma comparação negativa).

12) Hoje pela manhã, mamãe gastou $R \$ 28,00$ na feira. À tarde, ela gastou $R \$ 34,00$ no açougue. Quanto mamãe gastou hoje? (composição de duas transformações positivas).

13) Pedro colheu laranjas ontem. Hoje ele vendeu 110 laranjas e ficou com 85. Quantas laranjas ele colheu ontem? (busca do estado inicial de uma transformação negativa).

A tarefa foi realizada em duas sessões, durante o horário de aulas: na primeira, os escolares resolveram sete problemas; na segunda, seis problemas. Os resultados quantitativos do estudo foram analisados por meio do programa estatístico $R$ (R DEVELOPMENT CORE TEAM, 2010). Em todos os testes estatísticos empregados, o intervalo de confiança considerado foi de 95\%, e o nível de significância, de 5\% (alfa = 0,05).

\section{Resultados e discussão}

A comparação dos resultados dos dois grupos demonstrou que os respiradores orais tiveram maior dificuldade na resolução de problemas aditivos que os seus colegas de classe (Teste $t$ Pareado, $t=3,46$; graus de liberdade $=13$; média das diferenças $=3,07 ; \mathrm{p}<0,00$ ). 
Os tipos de erros cometidos pelos participantes foram: de atenção (At.), no algoritmo (Alg.), de interpretação (Int.), de interpretação e de atenção (Int. e at.), de interpretação e no algoritmo (Int. e alg.), de interpretação, de atenção e no algoritmo (Int., at. e alg.) e acerto casual (Ac. cas.).

O erro foi considerado como sendo de atenção quando o aluno demonstrou domínio do algoritmo, ou seja, usou corretamente a técnica operatória da adição ou da subtração em alguns problemas, mas cometeu um dos seguintes erros em algum item da tarefa:

a) tipo I: os números de uma ordem foram somados ou subtraídos incorretamente. Normalmente, o erro no cálculo foi por uma unidade. Por exemplo, no quinto problema, o respirador oral $\mathrm{n}^{\mathrm{o}} 5$ somou três unidades com oito e obteve 10 ao invés de 11 .

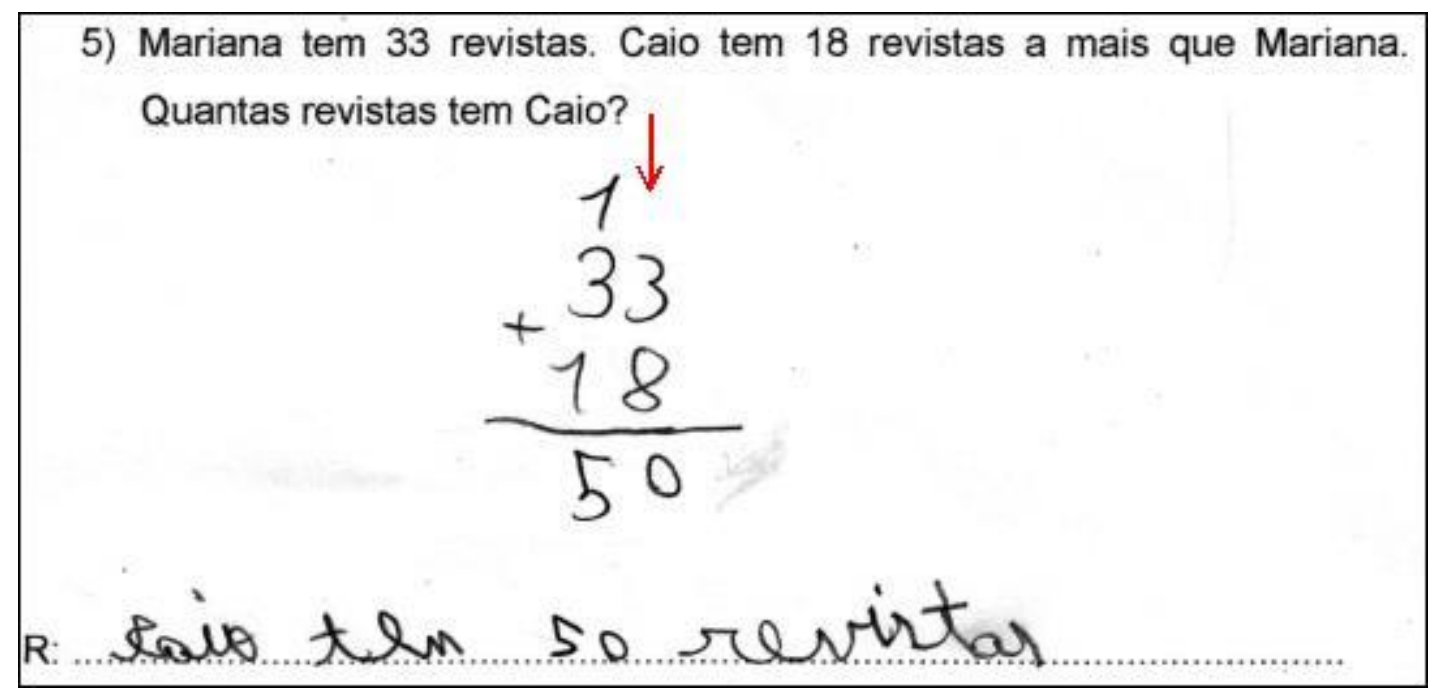

Figura 1 - Erro de atenção do tipo I cometido pelo respirador oral $n^{\circ} 5$

b) tipo II: o número fornecido no enunciado do problema foi trocado por outro visualmente semelhante. Por exemplo: no segundo problema, o colega de classe $n^{\circ} 39$ registrou 123 ao invés de 128.

2) Joăo tinha 128 carrinhos. Ele ganhou mais 35 . Com quantos carrinhos ficou?

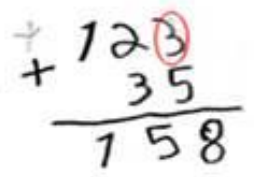

a 158 Carionhas

Figura 2 - Erro de atenção do tipo II cometido pelo colega de classe ${ }^{\circ} 39$ 
c) tipo III: a quantidade transportada foi registrada, mas não foi acrescentada às dezenas ou às centenas. Por exemplo, no segundo problema, o respirador oral $\mathrm{n}^{\circ} 22$ transportou uma (1) dezena, mas não adicionou-a às duas (2) e três (3) dezenas.

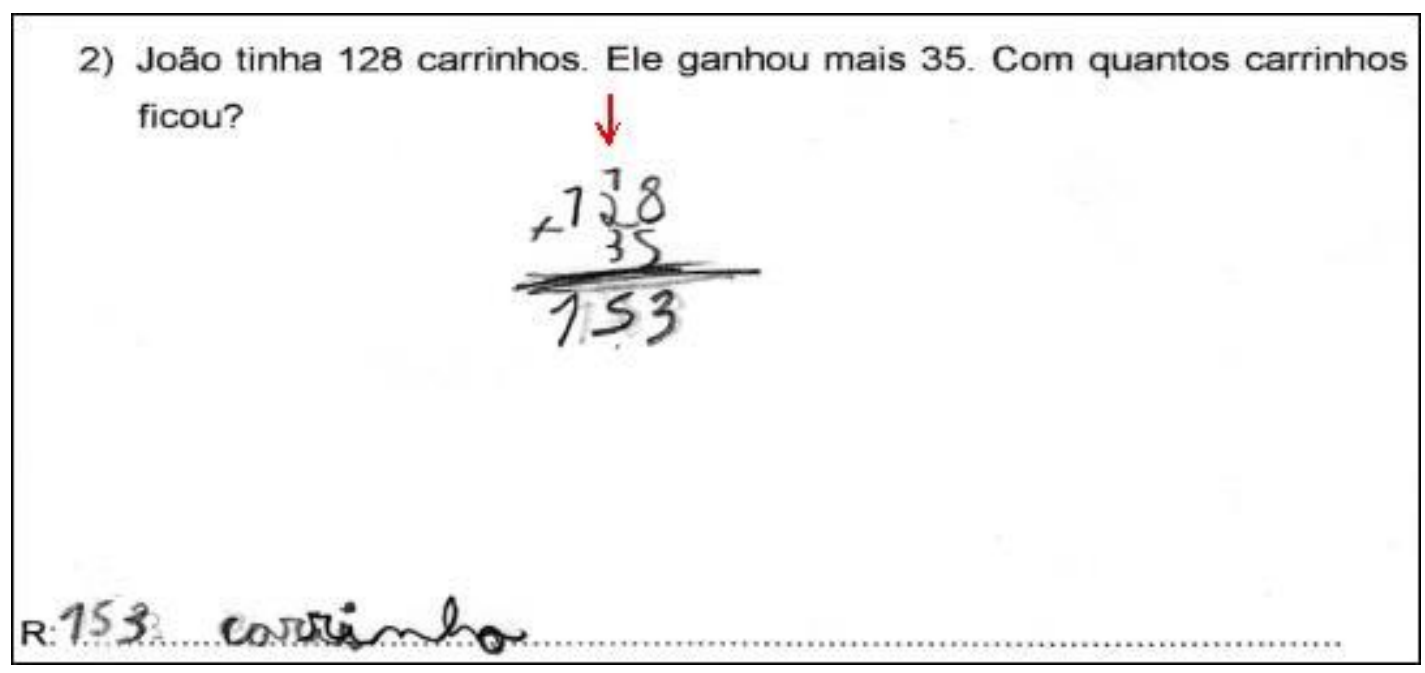

Figura 3 - Erro de atenção do tipo III cometido pelo respirador oral n ${ }^{\circ} 22$

d) tipo IV: em uma mesma operação foi realizada uma subtração e uma adição. Por exemplo, no terceiro problema, o colega de classe $\mathrm{n}^{\circ} 30$ subtraiu as unidades e as dezenas e somou as centenas $(112-104=208)$.

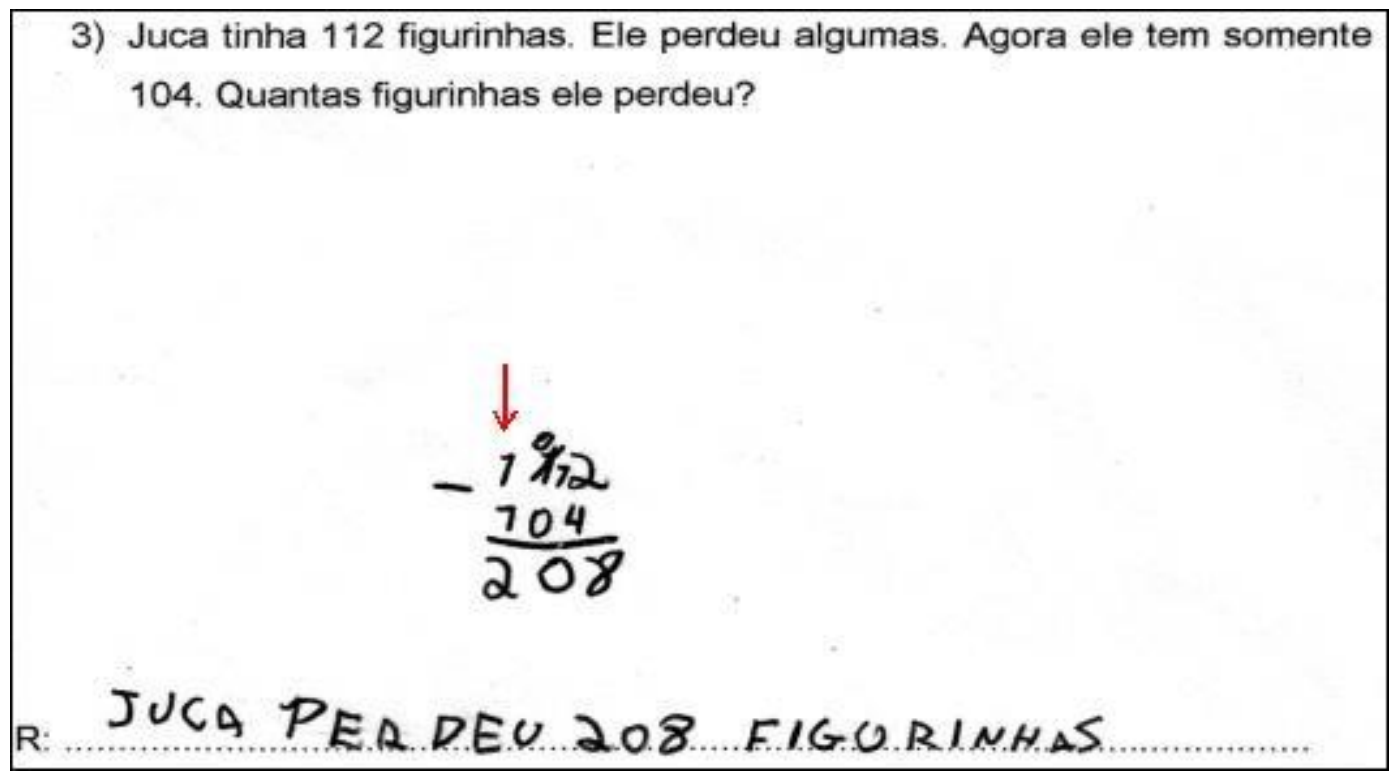

Figura 4 - Erro de atenção do tipo IV cometido pelo colega de classe n ${ }^{\circ} 30$

e) tipo V: uma adição foi efetuada como se fosse uma subtração, ou uma subtração como se fosse uma adição. Por exemplo, no terceiro problema, o colega de classe $n^{\circ} 31$ registrou uma subtração, mas realizou uma adição. 


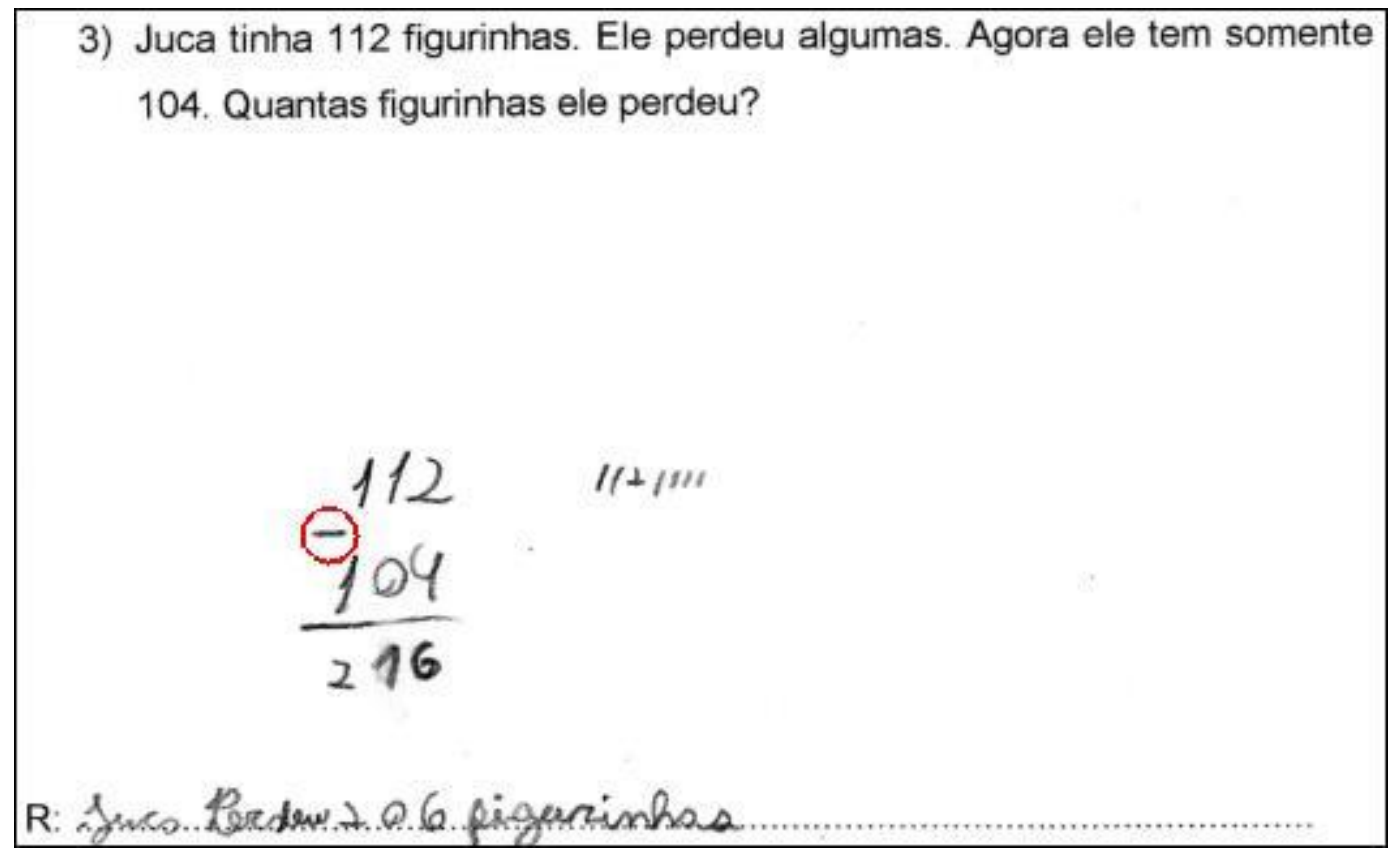

Figura 5 - Erro de atenção do tipo V cometido pelo colega de classe $n^{0} 31$

O segundo tipo de erro cometido pelos alunos foi no algoritmo, que ocorreu quando o aluno demonstrou, em mais de um problema, que não dominava a técnica operatória da adição ou da subtração. Os erros no algoritmo cometidos pelos grupos foram classificados em:

a) tipo I: subtração do maior valor do menor valor. Por exemplo, no sétimo problema, o respirador oral $\mathrm{n}^{\mathrm{o}} 23$ realizou a operação $8-26=22$.

7) Ana tem alguns brinquedos. Bruno tem 8 brinquedos a mais que Ana. No total, Bruno tem 26 brinquedos. Quantos brinquedos tem Ana?

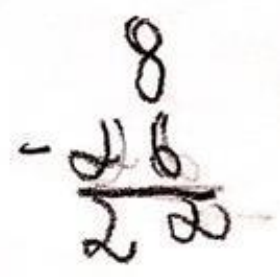

R:morian tenn d d lichaudo

Figura 6 - Erro no algoritmo do tipo I cometido pelo respirador oral $\mathrm{n}^{\mathrm{o}} 23$

b) tipo II: dificuldade de compreensão dos sentidos do zero (0). Por exemplo, no $13^{\circ}$ problema, o colega de classe $\mathrm{n}^{\mathrm{o}} 3$ adicionou zero às cinco unidades e, como resultado, obteve zero. 
13) Pedro colheu laranjas ontem. Hoje ele vendeu 110 laranjas e ficou com 85. Quantas laranjas ele colheu ontem?

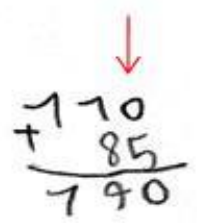

R: peare coleren 190 larajas entem.

Figura 7 - Erro no algoritmo do tipo II cometido pelo colega de classe $n^{\circ} 3$

c) tipo III: registro incorreto dos algarismos da segunda parcela sob os da primeira parcela. Por exemplo, no segundo problema, o respirador oral $\mathrm{n}^{\circ} 2$ registrou as unidades (5) da segunda parcela sob as dezenas (2) da primeira parcela, e as dezenas (3) da segunda parcela sob a centena (1) da primeira parcela $(128+35=478)$.

2) João tinha 128 carrinhos. Ele ganhou mais 35. Com quantos carrinhos ficou?

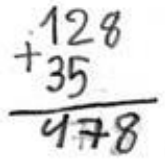

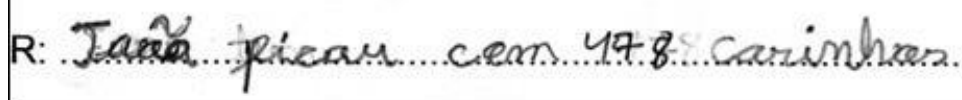

Figura 8 - Erro no algoritmo do tipo III cometido pelo respirador oral $n^{\circ} 2$

d) tipo IV: transporte da dezena ou da centena para a coluna (ordem) errada. Por exemplo, no segundo problema, o colega de classe $n^{0} 11$ somou as oito (8) unidades com as cinco (5) e obteve 13; depois, transportou uma (1) dezena para a ordem das unidades. 


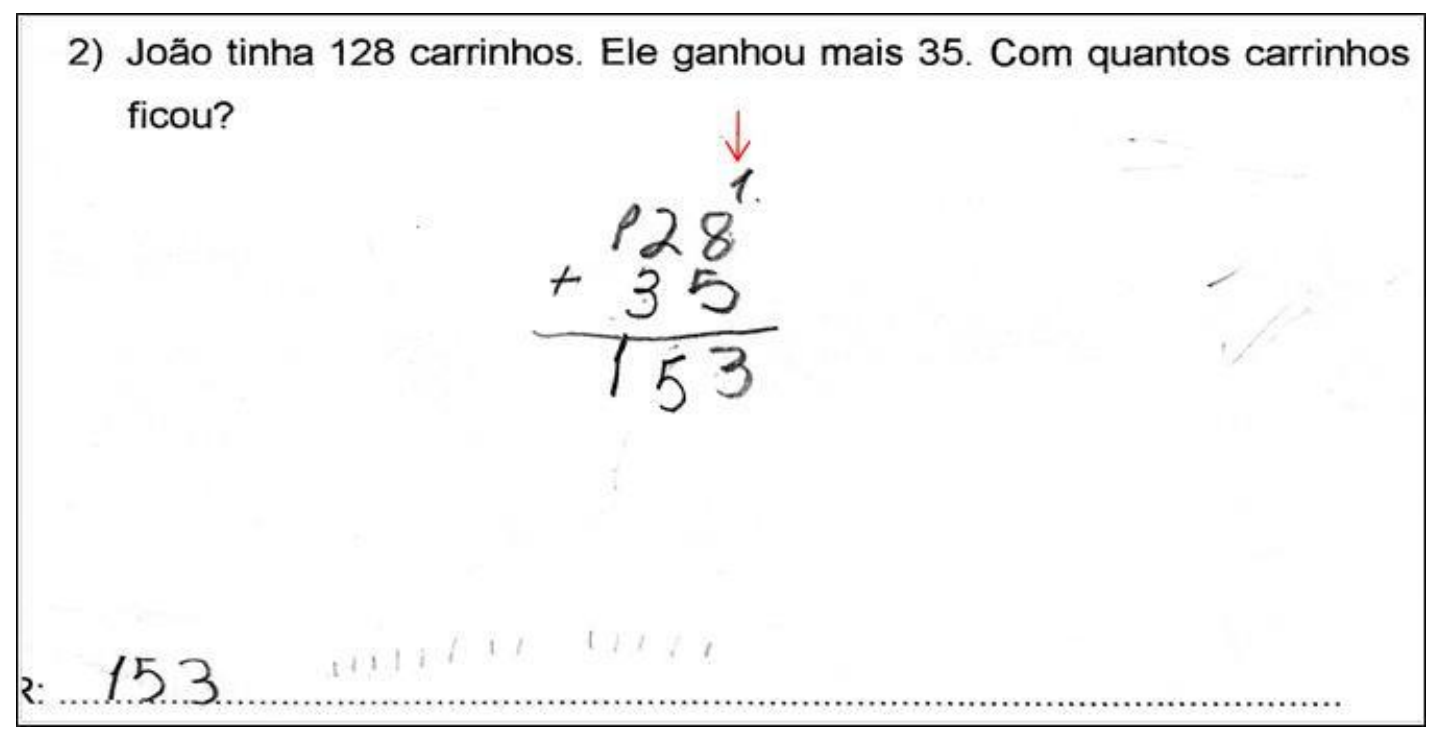

Figura 9 - Erro no algoritmo do tipo IV cometido pelo colega de classe $n^{\circ} 11$

O terceiro tipo de erro realizado pelos participantes foi o de interpretação, que ocorreu quando o aluno não identificou corretamente o tipo de operação que deveria ser utilizado para resolver o problema. Alguns exemplos de dificuldades de compreensão dos enunciados dos problemas são fornecidos a seguir:

a) no sexto e no nono problemas, a interpretação foi centralizada na palavra ganhar e, por isso, o aluno realizou uma adição ao invés de uma subtração. Por exemplo, no sexto problema $(95-40=55)$, o respirador oral $n^{\circ} 12$ explicou porque realizou uma adição da seguinte forma: "Como tá escrito ganhou, a continha é de mais." No nono item, o aluno respirador oral $\mathrm{n}^{\mathrm{o}} 1$ disse: "A menina tinha 18 bombons e ganhou mais 25 de presente. Então fica de mais porque ela ganhou e não perdeu."

b) no $12^{\circ}$ e no $13^{\circ}$ problemas, a interpretação foi centralizada, respectivamente, nas palavras gastar e vender e, por isso, o escolar realizou uma subtração ao invés de uma adição. Por exemplo, no $12^{\circ}$ problema o respirador oral $n^{\circ} 1$ justificou-se da seguinte forma: "Eu fiz de menos porque ela gastou esse dinheiro, ela não ganhou". No $13^{\circ}$ problema, o colega de classe n 9 explicou: "Eu fiz assim porque ele vendeu laranjas".

c) no quarto e no sétimo problemas, o aluno interpretou a expressão a mais como mais e, por isso, realizou uma adição ao invés de uma subtração. No quarto problema, o colega de classe $\mathrm{n}^{\circ} 3$ justificou-se da seguinte forma: "Essa continha ficou de mais porque tá falando 'a mais'; daí fica de mais." No sétimo problema, o colega de classe no 12 disse: "É assim porque é 'a mais'. Quando aparece 'a menos' é de menos.”

d) no sétimo problema, as 8 unidades foram interpretadas como multiplicador ou divisor, e o 26, como multiplicando ou dividendo. Para justificar a realização da divisão, o respirador oral n 17 disse: "É de dividir por causa dos números. O oito tá sozinho". O colega de turma n 4 explicou: "Quando tem só um número, a professora falou que pode se de vezes ou dividir". 
e) no oitavo problema $(50-23=27)$, o aluno interpretou o terceiro estado (50 frutas) como sendo um dos estados iniciais. Por exemplo, o respirador oral $n^{\circ} 2$ disse: "Eu fiz assim ó: 50 caixas mais as 23 maçãs. Daí o que deu foi 73 bananas".

Além de erros de atenção, no algoritmo e de interpretação, os alunos também realizaram erros simultâneos, de interpretação e de atenção (Int. e at.), de interpretação e no algoritmo (Int. e alg.) e, ainda, de interpretação, de atenção e no algoritmo (Int., at. e alg.). Também foram registrados acertos casuais (Ac. cas.), que ocorreram quando o aluno resolveu corretamente o problema, mas demonstrou ter escolhido, aleatoriamente, a operação. Por exemplo: no quinto problema $(33+18=51)$, o colega de classe $n^{\circ} 11$ justificou-se dizendo: "Essa aqui eu escolhi fazer de mais".

Entre os 229 erros cometidos pelo grupo de respiradores orais, 30,13\% foram de atenção e 7,42\%, de interpretação e no algoritmo (Int. e alg.); entre os 238 erros realizados pelo grupo de colegas de classe, $18,90 \%$ foram de atenção e $17,22 \%$, de interpretação e no algoritmo (Int. e alg.). Portanto, a dificuldade de atenção prejudicou mais o desempenho dos respiradores orais que o de seus colegas de classe (Teste para Comparação de Duas Proporções, $\mathrm{p}<0,00$ ), e a dificuldade de interpretação e no algoritmo (Int. e alg.) prejudicou mais estes que aqueles $(\mathrm{p}<0,00)$. Os dois grupos apresentaram proporções semelhantes de erros de interpretação $(\mathrm{GRO}=35,50 \% ; \mathrm{GCC}=37,40 \% ; \mathrm{p}<0,25)$ e no algoritmo $(\mathrm{GRO}=$ $19,21 \%$; GCC $=19,31 \% ; \mathrm{p}<0,48)$.

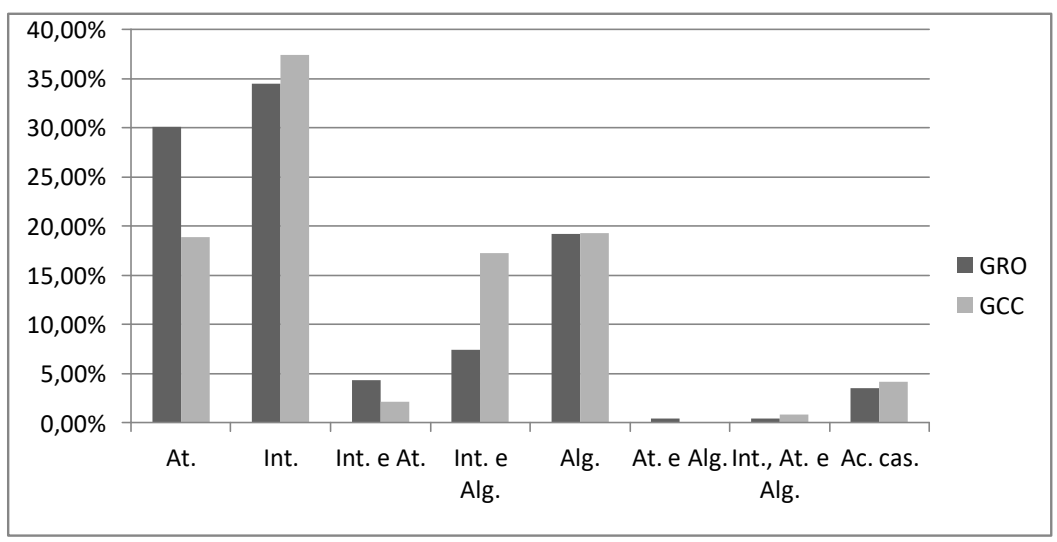

Figura 10 - Comparações das porcentagens dos tipos de erros cometidos pelos grupos ${ }^{1}$

Assim como observado no estudo de Godoy (2003), os respiradores orais apresentaram, principalmente, dificuldades de atenção seletiva e sustentada. A dificuldade de seleção de informações pode ter contribuído para que os alunos registrassem a quantidade transportada, mas não a acrescentassem às dezenas ou às centenas (erro tipo III). Por exemplo,

\footnotetext{
${ }^{1}$ Nota: valores de p significativos para erros de atenção e erros de interpretação e no algoritmo.
} 
no segundo problema, o respirador oral $\mathrm{n}^{\mathrm{o}} 22$, após registrar o 1 (dezena), deslocou o foco de sua atenção para as dezenas 20 e 30, e fixou-se nesse conjunto. Dessa forma, a dezena transportada tornou-se um estímulo secundário e, por isso, não foi adicionada às outras dezenas.

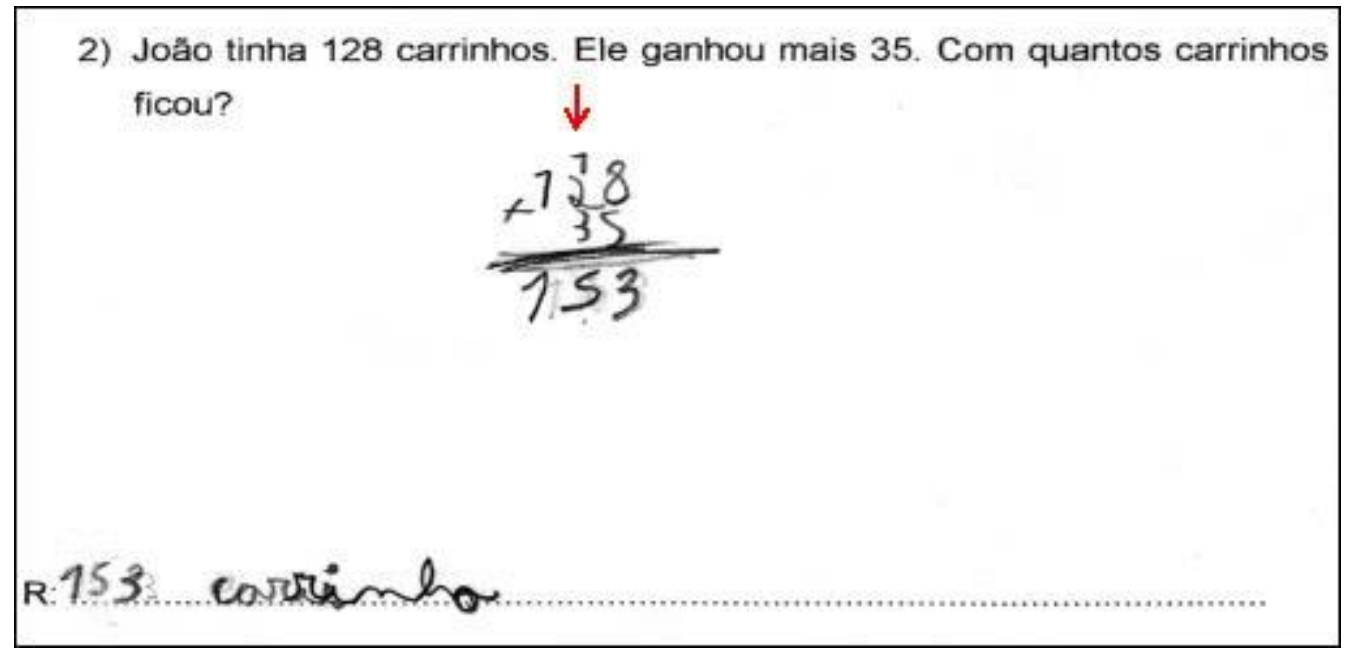

Figura 11 - Erro de atenção seletiva cometido pelo respirador oral $\mathrm{n}^{\mathrm{0}} 22$

A dificuldade de concentração e de seleção de estímulos visualmente semelhantes pode ter levado os alunos a cometerem erros dos tipos II e V. Por exemplo, no quarto problema $(24-17=8)$, o respirador oral $\mathrm{n}^{\circ} 17$ registrou 25 ao invés de 24 , e o respirador oral $\mathrm{n}^{\mathrm{o}} 26$ registrou $24-17$, mas realizou uma adição $(24+17=40)$.

Em relação aos erros de atenção I e IV, a dificuldade de sustentar a atenção pode ter levado, no $5^{\circ}$ problema $(33+18=51)$, o respirador oral $\mathrm{n}^{\circ} 5$ a errar, por uma (1) unidade, a soma $3+8=10$; e no $3^{\circ}$ problema $(112-104=208)$, o respirador oral $\mathrm{n}^{\mathrm{o}} 15$ a subtrair as unidades e as dezenas, e a somar as centenas $(112-104=208)$.

Os respiradores orais cometeram mais erros de atenção que no algoritmo (Teste Binomial Exato, At. = 61,07\%; Alg. = 38,93\%; p < 0,01), e os colegas de classe, mais erros de interpretação que de atenção (Int. $=66,41 \%$; At. $=33,59 \% ; \mathrm{p}<0,00$ ). Portanto, uma característica que diferenciou os grupos foi a dificuldade de atenção dos respiradores orais. Uma semelhança foi a dificuldade de interpretação dos problemas.

A análise do material escolar dos alunos revelou que os professores não seguiram as recomendações dos PCN (BRASIL, 1997b), ou seja, não ensinaram os diferentes significados da adição e da subtração: $72,14 \%$ dos problemas registrados nos cadernos eram dos tipos mais simples, que exigiam a busca do terceiro estado ou do estado final. Os professores haviam ensinado as ideias tradicionais da adição (junção e acréscimo).

Alguns exemplos ilustram a dificuldade dos escolares em compreender problemas pouco trabalhados em sala de aula. Ao resolver o terceiro problema (valor da transformação negativa), o respirador oral $n^{\circ} 2$ argumentou: "Essa eu não consigo fazer. Tem que inventar um número? Vou fazer de menos, já que ele perdeu mesmo”. Ao realizar o sétimo problema 
(referente de uma comparação), o colega de classe n ${ }^{\circ} 14$ justificou-se: "Eu achei difícil porque não fala quanto a Ana tem".

A escola ensina que palavras-chave contidas nos enunciados identificam o tipo de operação a ser realizada. Ganhar, comprar e juntar são ensinadas como sinônimas de adicionar, e perder, vender e gastar, de subtrair. É como se as palavras-chave, segundo Vasconcelos (1998), devessem ser utilizadas como regras para a escolha dos tipos de operações a serem efetuadas. O colega de classe $n^{0} 4$ disse: "Minha professora falou que quando tem 'fugiu, sumiu, comeu, perdeu', é de menos. 'Voltou, chegou, ganhou', é de mais".

Em um problema de busca do valor da transformação, o termo ganhou não é sinônimo de adição. Por exemplo: Paula tinha 18 bombons. Ela ganhou mais alguns de sua mãe e ficou com 25. Quantos bombons Paula ganhou? (nono problema). Nesse caso $(18+\mathrm{x}=25)$, o aluno deve compreender que, apesar de ter sido descrita uma situação de transformação positiva (acréscimo), para resolver o problema é preciso utilizar uma operação inversa (25 $18=7$ ). A dificuldade para compreender a adição como o inverso da subtração, e esta como o inverso daquela, fez com que $66,67 \%$ dos respiradores orais e $67,85 \%$ dos colegas de classe não conseguissem resolver corretamente esse problema.

$\mathrm{Na}$ ausência de uma palavra-chave que orientasse a identificação da operação, alguns alunos utilizaram os números na sequência fornecida no enunciado: Em uma caixa há 50 frutas. 23 frutas são maçãs e o restante são bananas. Quantas bananas há nessa caixa? (oitavo problema). O colega de turma $\mathrm{n}^{\mathrm{o}} 28$ justificou-se da seguinte forma: "Quando tem o problema, primeiro eu leio, e depois eu escrevo os números na ordem que aparecer. Daí eu fiz $\operatorname{assim}(50+23=73)$ para saber quantas bananas ia dar".

Como a escola não enfatiza o trabalho de interpretação e de busca de estratégias, muitos alunos acreditam que resolver problemas signifique fazer cálculos com os números fornecidos no enunciado. No $13^{\circ}$ problema, de busca do estado inicial de uma transformação negativa $(110+85)$, o colega de classe $n^{\circ} 11$ explicou: "Eu fiz a conta assim (subtração) porque eu tava fazendo muito (problemas) de mais. Eu sei fazer de menos". Ao fazer o quarto problema $(24-17=7)$, o colega de classe $n^{\circ} 10$ argumentou: "Como tem dois números iguais (duas dezenas) pode ser de mais ou de menos. Eu escolhi de mais. Se fosse 24 e 7 seria de vezes ou de dividir".

Outro problema, ainda não superado nas escolas, relaciona-se ao ensino de operações centrado no uso mecânico de algoritmos. De acordo com Parâmetros Curriculares Nacionais, a escola deve estimular a resolução das operações com números naturais por meio de estratégias pessoais, e a compreensão dos processos envolvidos no uso de técnicas operatórias convencionais (BRASIL, 1997b).

Ao escreverem as contas armadas, muitos alunos registraram os números na sequência em que eles foram fornecidos nos enunciados e, por isso, em alguns casos, o subtraendo ficou sendo maior que o minuendo. No $12^{\circ}$ problema, de composição ou misto $(28+34)$, o colega de classe $n^{\circ} 42$ realizou uma subtração $(28$ - 34). Ao ser questionado se era possível tirar 34 de 28, respondeu: "Eu não tirei o 34 do 28 . Eu tirei o quatro do oito e o 3 do 2". Isso 
demonstra que o aluno tem dificuldade em compreender o conceito de valor posicional e que, para tirar o menor valor do maior, inverteu a posição dos algarismos da ordem das dezenas.

Esse tipo de dificuldade também foi observado por Queiroz e Lins (2011), que avaliaram adolescentes da Educação de Jovens e Adultos, do oitavo e ao nono ano do Ensino Fundamental, de Pernambuco: o erro mais realizado pelos alunos foi o de inversão, ou seja, $34 \%$ dos erros consistiram na troca do algarismo do minuendo pelo do subtraendo.

Outra dificuldade observada no grupo avaliado neste estudo foi a de compreensão do sentido do zero (0). Por exemplo, no $13^{\circ}$ problema $(110+85=195)$, o colega de classe $n^{\circ} 3$ adicionou zero às cinco unidades e, como resultado, obteve zero. No estudo de Queiroz e Lins (2011), o segundo tipo de erro mais realizado (30\%) pelos adolescentes ocorreu nas operações que continham zero no minuendo ou no subtraendo.

\section{Considerações finais}

A investigação realizada por Kazakevich, Neves e Kajihara (2008) revelou que os efeitos da respiração oral podem ser observados precocemente no desenvolvimento infantil: crianças pequenas, da faixa etária de 3 a 5 anos, já apresentavam problemas decorrentes da mudança do padrão respiratório. Os resultados desta pesquisa, realizada com 26 respiradores orais que participaram daquele estudo, sugerem que dificuldades de matemática também podem ser observadas no início da escolarização.

Ao longo da década de 2000, o Grupo de Pesquisa "Ensino, Aprendizagem e Avaliação Escolar", da Universidade Estadual de Maringá, observou que a dificuldade de atenção é uma característica que distingue respiradores orais do quarto, quinto e sexto anos do Ensino Fundamental de seus colegas de classe. Os resultados do presente estudo demonstraram que já no terceiro ano é possível observar a interferência da desatenção na resolução de problemas matemáticos. Portanto, o respirador oral necessita de um atendimento educacional para desenvolver a atenção.

O desconhecimento das causas e das consequências da mudança do padrão respiratório nasal impede que os professores identifiquem o aluno respirador oral em sala de aula e que compreendam suas dificuldades. No período de aplicação da tarefa de resolução de problemas, por exemplo, alguns professores demonstraram interesse pelo tema deste estudo e, a partir das informações fornecidas pela pesquisadora, procuraram identificar alunos com características de respiração oral. Um dos professores relatou que um de seus alunos parecia estar sempre gripado e que, até então, desconhecia que ele poderia ter rinite alérgica.

O professor que conhece os sintomas das doenças obstrutivas e as alterações decorrentes da respiração oral pode orientar os familiares a buscarem ajuda de um especialista. O tratamento médico da rinite alérgica e da hipertrofia das tonsilas faríngeas é fundamental para que a criança volte a respirar pelo nariz, assim como o atendimento educacional é necessário para o desenvolvimento da capacidade de atenção. 
Um fator que tem prejudicado tanto o desenvolvimento do campo conceitual aditivo dos respiradores orais quanto de seus colegas de classe é a qualidade de ensino. Quinze anos após a publicação dos Parâmetros Curriculares Nacionais (BRASIL, 1997b), os cadernos escolares comprovam que poucos problemas são trabalhados durante o ano letivo e somente os significados mais simples da adição e da subtração são ensinados: esta, como sinônimo de perda, e aquela, de junção.

Dorne (2013), por exemplo, analisou os cadernos de dez turmas de quatro escolas do noroeste do Paraná, e verificou que a média de problemas trabalhados durante o terceiro ano do Ensino Fundamental foi de 34,7. Houve grande variação na quantidade de problemas trabalhados: uma turma resolveu somente 4 problemas durante o ano letivo; três turmas resolveram de 21 a 24 problemas; três turmas, de 34 a 37 problemas; e três turmas, de 53 a 59 problemas. Os tipos de problemas aditivos mais trabalhados pelos professores foram de busca do todo de uma combinação e de busca do estado final de uma transformação negativa, e os menos trabalhados, de comparação e de composição (misto).

A formação dos professores que irão atuar nos anos iniciais do Ensino Fundamental precisa ser repensada. Em relação à Matemática, é importante, por exemplo, que a Teoria dos Campos Conceituais seja incluída nos conteúdos ministrados nos cursos de Pedagogia, para que os professores tenham ferramentas para desenvolver os campos conceituais de seus alunos. Isso significa romper com a ênfase dada à instrumentação pedagógica, na disciplina de Metodologia do Ensino da Matemática, dos cursos de graduação em Pedagogia, que não tem garantido uma formação teórica adequada em relação aos conhecimentos matemáticos a serem ensinados no Ensino Fundamental (ALMEIDA; LIMA, 2012).

\section{Referências}

ALMEIDA, M. B. de A.; LIMA, M. das G. de. Formação inicial de professores e o curso de pedagogia: reflexões sobre a formação matemática. Ciência \& Educação, Bauru, v. 18, n. 2, p. 451-468, 2012.

BRASIL. Ministério da Educação. Secretaria de Educação Fundamental. Parâmetros curriculares nacionais: introdução aos parâmetros curriculares nacionais. Brasília: 1997a. Disponível em: $<$ http://portal.mec.gov.br/seb/arquivos/pdf/livro01.pdf $>$. Acesso em: $20 \mathrm{fev}$. 2013.

BRASIL. Ministério da Educação. Secretaria de Educação Fundamental. Parâmetros curriculares nacionais: matemática. Brasília: 1997b. Disponível em: <http://portal.mec.gov.br/seb/arquivos/pdf/livro03.pdf>. Acesso em: 20 fev. 2013.

BREUER, J. El paciente respirador bucal. Revista de la Associación Odontológica Argentina, Buenos Aires, v. 77, n. 3-4, p. 102-106, 1989. 
BROZEK, J. L. et al. Allergic rhinitis and its impact on asthma (ARIA) guidelines: 2010 revision. Journal of Allergy and Clinical Immunology, New York, v. 126, n. 3, p. 466-76, Sep. 2010.

COREY, J. P.; HOUSER, S. M.; NG, B. A. Nasal congestion: a review of its etiology, evaluation, and treatment. Ear, Nose and Throat Journal, New York, v. 79, n. 9, p. 690-701, Sep. 2000.

DORNE, S. R. Resolução de problemas matemáticos por alunos respiradores orais. 2013. 127 f. Dissertação (Mestrado em Educação) - Universidade Estadual de Maringá, Maringá, 2013.

ENDO, L. H. Adenoamigdalites. In: BOTELHO, J. B. (Org.). Otorrinolaringologia e cirurgia de cabeça e pescoço. Manaus: Editora da Universidade do Amazonas, 2000. p. 111130.

GIL, A. C. Métodos e técnicas de pesquisa social. 6 ed. São Paulo: Atlas, 2008.

GODOY, M. A. B. Problemas de aprendizagem e de atenção em alunos com obstrução das vias aéreas superiores. 2003. 123 f. Dissertação (Mestrado em Educação) - Universidade Estadual de Maringá, Maringá, 2003.

GOMES, T. S. Avaliação do desenvolvimento escolar de alunos respiradores orais. 2007. 93 f. Dissertação (Mestrado em Educação) - Universidade Estadual de Maringá, Maringá, 2007.

KAZAKEVICH, J. G.; NEVES, J. A.; KAJIHARA, O. T. Respiração oral em crianças da Educação Infantil, 2008, 34 f. Relatório final de pesquisa de iniciação científica Universidade Estadual de Maringá, Maringá, 2008.

LEAL, L. D. A hipertrofia das tonsilas faríngeas e suas repercussões na atenção e na aprendizagem escolar. 2004. 77 f. Dissertação (Mestrado em Educação) - Universidade Estadual de Maringá, Maringá, 2004.

LUZZI, V. et al. Allergic rhinitis as a possible risk factor for malocclusion: a case-control study in children. International Journal of Paediatric Dentistry, Hoboken, v. 23, n. 4, p. 274-278, Jul. 2013.

McCOY, J. D.; SHEPHARD, E. E. Applied orthodontics. 2 ed. Philadelphia: Lea and Febiger, 1956.

McNAMARA, J. A. Influence of respiratory pattern on craniofacial growth. Angle Orthodontist, Newton N., v. 51, n. 4, p.269-300, Oct. 1981. 
MOTA, M. M. P. E. da. Metodologia de pesquisa em desenvolvimento humano: velhas questões revisitadas. Psicologia em Pesquisa, Juiz de Fora, v. 4, n. 2, p. 144-149, jul.-dez. 2010 .

NATHAN, R. A. The burden of allergic rhinitis. Allergy and Asthma Proceedings, Providence, v. 28, n. 1, p. 3-9, Jan.-Feb. 2007.

NISHIMURA, C. M. Avaliação da voz e da aprendizagem de crianças respiradoras orais. 2010. 110 f. Dissertação (Mestrado em Educação) - Universidade Estadual de Maringá, Maringá, 2010.

PORTINHO, F. Principais problemas otorrinolaringológicos na criança. In: LIMA, J. (Org.). Pediatria essencial. 5 ed. Rio de Janeiro: Atheneu, 1999. p. 749-753.

POTSIC, W. P. Assessment and treatment of adenotonsillar hypertrophy in children. American Journal of Otolaryngology, Philadelphia, v. 13, n. 5, p. 259-264, Sep.-Oct. 1992.

QUEIROZ, S.; LINS, M. A aprendizagem de matemática por alunos adolescentes na modalidade educação de jovens e adultos: analisando as dificuldades na resolução de problemas de estrutura aditiva. Bolema, Rio Claro, v. 24, n. 38, p. 75-96, abr. 2011.

R DEVELOPMENT CORE TEAM: a language and environment for statistical computing. Vienna: R Foundation for Statistical Computing, 2010. Disponível em: <http://www.Rproject.org>. Acesso em: 25 nov. 2011.

RICKETTS, R. M. Respiratory obstruction syndrome. American Journal of Orthodontics, New York, v. 54, n. 7, p. 495-507, Jul. 1968.

RUBIN, R. M. Facial deformity: a preventable disease? The Angle Orthodontist, Newton N., v. 49, n. 2, p. 98-103, Apr. 1979.

SÁ FILHO, F. P. G. de. Síndrome da respiração oral. In: (Org.). As bases fisiológicas da ortopedia maxilar. São Paulo: Santos, 1994. p. 81-93.

SILVA, M. D. dos S. Problemas de aprendizagem em escolares com rinite alérgica. 2005. 104 f. Dissertação (Mestrado em Educação) - Universidade Estadual de Maringá, Maringá 2005.

SOLÉ, D.; SAKANO, E. III Consenso brasileiro sobre rinites - 2012. Brazilian Journal of Otorhinolaryngology, São Paulo, v. 75, n. 6, p. 1-51, nov.-dez. 2012. Suplemento.

SOLOW, B.; SIERSBAEK-NIELSEN, S. Cervical and craniocervical posture as predictors of craniofacial growth. American Journal of Orthodontics Dentofacial Orthopedics, New York, v. 101, n. 5, p. 449-458, May 1992. 
SUBTELNY, J. D. The significance of adenoid tissue in orthodontia. The Angle Orthodontist, Newton N., v. 24, n. 2, p. 59-69, Apr. 1954.

VASCONCELOS, L. Problemas de adição e de subtração: modelos teóricos e práticas de ensino. In: SCHLIEMANN, A.; CARRAHER, D. W. (Orgs.). A compreensão de conceitos aritméticos: ensino e pesquisa. Campinas: Papirus, 1998. p. 53-72.

VERGNAUD, G. Os problemas de tipo aditivo. In: (Org.). A criança, a matemática e a realidade: problemas de ensino da matemática na escola elementar. Curitiba: Ed. da UFPR, 2009. p. 197-222.

Recebido em: janeiro 2014

Aprovado para publicação em: julho 2014 